\title{
En torno a un tema: La infalibilidad
}

E. CASTELLI y colaboradores, L' Infallibilitá. L' aspetto filisofico $e$ teologico. Atti del convegno indetto dal Centro Internazionale di Studi Umanistici e dall' Instituto di Studi Filosofici. Roma, 5-12 Gennaio 1970.

$25 \times 18,624$ p.

KUNG, H., Unfehlbar? Eine Anfrage. Benziger Verlag, Zürich 1970. $20 \times 15,204 \mathrm{p}$.

Infallibile? Una domanda. Anteo, Bologna 1970, $20 \times 13,292 \mathrm{pp}$.

Cuando uno se encuentra ante una serie de libros en torno a un tema, cuando este tema despierta un interés en los medios estudiosos, cuando las revistas especializadas se hacen eco del mismo, cuando los cristianos adultos se interrogan sobre sus posibles aspectos, enfoques y consecuencias... necesariamente hay que pensar, al menos por honradez, que algo existe a lo que no se ha dado plenamente solución.

La constitución dogmática "PASTOR AETERNUS" de Ecclesia Christi, promulgada en la sesión IV del Concilio Vaticano I, 18 de Julio, 1870 (D. 3050-3075), parecía en aquella época que iba a cerrar para siempre el problema. El afán de la mayoria infalibilista "estimaba normal que se aprovechase la reunión del Concilio para cortar por lo sano el despertar de las controversias en la materia, que juzgaban perfectamente estériles" (R. Aubert, Vaticano I. Edit. Eset, Vitoria 1970, p. 121). Razones de diversa índole apoyaban la postura de esta sección de padres conciliares. Junto a las razones teológicas se apiñaban un haz de conveniencias: devoción hacia Pío IX, afincamiento del principio de autoridad en un ambiente político animado por el nacimiento de ideas democráticas, búsqueda de un refugio junto al jefe frente a los ataques que recibía continuamen- 
te la sede de Roma etc. El inquieto y político arzobispo de Westminster Mons Manning jugaba la baza con todas sus armas, que eran muchas. Frente a esta "mayoria" se encontraba la "minoria" que, en principio, llegó a componer un veinte por ciento de los padres asistentes, entre los que figuraban los nombres de Doupanloup, Hefele y el cerebro laico Lord Acton, discípulo de Döllinger, afanoso en unir a los principales jefes de la oposición. Estos grupos de oposición, compuestos también por padres de diferente índole y proveniencia, fundamentaban asimismo su postura en una serie de razones que van desde la teología hasta la política: concepción semigalicana del magisterio de la Iglesia, tradición de Bossuet, miedo a que el episcopado quedara prácticamente aniquilado, dificultades de tipo histórico (caso del Papa Honorio), dificultades sobre el mundo del ecumenismo en especial lo relativo a los ortodoxos, salvaguardar el episcopado como un elemento esencial de la estructura divina de la jerarquía. Los padres de la "minoría" tenían su miedo de terminar el Concilio como "sátrapas de un autócrata, cuando habían llegado a él como príncipes de la Iglesia", en expresión humorista del obispo de Liverpool.

La corriente curial, partidaria en general de la infalibilidad, iba conduciendo las aguas por los cauces que más le convenía. En la elección de los miembros de las comisiones, principalmente de la comisión dogmática, se ven eliminados aquellos padres que aparecen reaccionarios a la definición, a la vez que se daba cábida a personas faltas de competencia y dedicación teológica (Cfr. Aubert, p. 134). El "facti sumus opprobium in Ecclesia..." salido de boca de un jefe de la oposición no fue simplemente un grito de fracaso, sino que tenía su fundamentación en la actuación quizás demasiado humana del grupo dirigente de la mayoría.

Aunque, al parecer, el Concilio había sido reunido por el Papa y sus colaboradores para hacer frente al racionalismo de la época, lo cierto es que la posibilidad de una propuesta de definición acerca de la infalibilidad iba creciendo cada día. Las cosas adquirieron un cariz tan complicado que aquello tenía en ocasiones aspectos de campaña electoral, tanto dentro como fuera de la ciudad de Roma. Las Römische Briefe que a partir de mediados de diciembre de 1869 aparecen en el Allgemeine Zeitung de Augsburg firmadas por "Quirinus", seudónimo bajo el que se encubría Döllinger, eran noticias acerca de la vida conciliar llegadas a sus manos por diversos conductos, aunque siempre con la misma orientación: mantener la postura de la minoría opuesta a la infalibilidad. 
Las críticas suscitadas contra el primer esquema "De Ecclesia" demuestran que los miembros de la "minoría" eran hombres cultos, enterados de las cuestiones teológicas, investigadores de la historia de la Iglesia. Achacan al esquema una perspectiva anticolegial, la ausencia de una teologia del episcopado en el capítulo dedicado a la jerarquía, la visión eminentemente lógica de la Iglesia como sociedad y la pobre perspectiva histórica del pueblo de Dios. Fue una pena que la segunda elaboración del esquema no llegara a manos de los padres. Las presiones poco nobles de la mayoría convencieron a Pío IX, cosa que él también deseaba, para que se comenzara la discusión por el tema del Romano Pontífice. Los cuatro capítulos que aparecen en la constitución Pastor aeternus fueron los únicos temas que se discutieron. El 6 de marzo se comunicaba a los Padres la inclusión de un capítulo complementario que deberia ponerse a continuación del capítulo $\mathrm{XI}$ del esquema sobre la Iglesia. $\mathrm{Y}$ el 15 de junio se abordaba en el aula conciliar el problema de la infalibilidad con el fin de "barrer para siempre los restos de galicanismo". Como las tensiones seguían siendo fuertes, se llega a un acuerdo de manera oficiosa entre los jefes de las diversas tendencias: incluir en el texto la frase "utens consilio et requirens adiutorium universalis Ecclesiae"; pero Pío IX pronunciaba entonces aquellas desacertadas palabras: la tradición soy yo. La Comisión central se niega el 20 de junio a hacer mención del consentimiento de los obispos cuando se trata del privilegio de infalibilidad del Romano Pontífice. No falta quien suscita la idea y la posibilidad de incluir un doble sujeto de infalibilidad: el Papa solo y el colegio episcopal; pero la idea no prospera. El tiempo urge, ya que los calores de Roma son duros en esas calendas. Por fin, la redacción final del esquema accede a algunos retoques con el fin de quitar los miedos existentes en algunos miembros de la "minoria" y para no presentar al Papa como "separado de la Iglesia en el ejercicio de la infalibilidad". Monseñor Gasser, en nombre de la comisión de la fe, presenta el 11 de julio un informe en el que explica de manera amplia y con altura teológica las modificaciones, acentuando a la vez los derechos de los obispos, la íntima unión del Papa a la Iglesia y las condiciones precisas para el ejercicio de la infalibilidad papal. No obstante, se excluye el "consensus Ecclesiarum".

La votación del día 13 de julio sobre el conjunto del proyecto presenta un aparente fracaso: 50 padres no asisten al aula conciliar; de los 600 presentes 88 votan "non placet" y 72 votan el "placet juxta modum". La reacción de Pío IX es dura y, por su consejo, se in- 
cluye en el decreto el "non ex consensu Ecclesiae". A pesar de las tentativas, en última instancia, de Doupanloup y Rauscher presentando a Pío IX los peligros de una definición bajo pena de anatema, nada pudo hacerse. A los miembros de la "minoria" solamente les queda la opción de no asistir al aula conciliar el día 18 de julio, fecha señalada para la votación final y aprobación definitiva del esquema. $\mathrm{Y}$ así sucedió. El día 18, están presentes en San Pedro solamente 535 padres conciliares. Pero poco a poco los adictos a la postura anti-infalibilista van cediendo y sometiéndose al esquema votado, salvo raras excepciones de pertinacia como la de Döllinger. El concilio se prorroga "sine die" en vista de los acontecimientos políticos que surgen. Merced a eso no se discute ni se vota el anteproyecto sobre el episcopado, redactado de una manera un tanto pobre. Podríamos pensar ¿qué hubiera pasado en el Vaticano II de haberse llevado a cabo la discusión sobre el ministerio episcopal en el Vaticano I? El esquema mantenía una postura anticolegial "e insistía en el hecho de que no es el colegio de los apóstoles el que posee el poder supremo en la Iglesia, sino Pedro, en tanto que Vicario de Cristo, distinto por ese título de sus hermanos" (Cfir. Aubert, p. 216).

Así quedaron las cosas. Los manuales de teología se dedicaron exclusivamente a presentar una eclesiología plasmada en los capítulos de la constitución Pastor aeternus y a partir de entonces "las nociones de magisterio e infalibilidad han conocido un desarrollo excesivo que lleva consigo algo de ficción" (Congar, Infaillibilité et indefectibilité, en Rev. Sc. Ph. Th. LIV, 4, 1970 p. 617-618).

Pero el tiempo pasa. $Y$ no en balde. Las categorias mentales y las situaciones históricas del s. XIX se van transformando a través de los años. $Y$ surge nuestro siglo moderno, con ideas de dinamismo e historia, de democracia y responsabilidad del pueblo, con sentido del quehacer humano, con investigaciones críticas sobre el pasado cristiano. Todo esto tiene necesariamente que influir en la visión de la teología, de la comunidad cristiana, en la labor de los investigadores. El tema de la infalibilidad, punto fuerte de contraste con otros hermanos cristianos, ocupa en estos últimos años un puesto de honor en reuniones y discusiones, en mesas de trabajo y en la inquietud de los estudiosos. Aparecen multitud de libros sobre el tema. $Y$ con ocasión del año centenario de la definición del Vat. I aparece, de manera un tanto vehemente, un libro, firmado por el profesor de la Universidad de Tübingen Hans Küng, con el título UNFEHLBAR? Eine Anfrage. Sobre él hablaremos en seguida. Pero antes vamos a. 
presentar algunas ideas plasmadas en las conferencias y en las discusiones de la reunión del Centro Internacional de Estudios humanísticos, celebrada en Roma del 5 al 12 de enero de 1970 y recogidas en voluminoso tomo dirigido por Enrico Castelli.

I. Reunión de Roma: 5-12 de enero, 1970.

Bajo el título genérico Infalibilidad: Aspecto filosófico y teológico se recogen en el libro una serie de aportaciones estupendas, abriendo nuevos cauces a toda esta problemática. Es más, dada la situación actual de la cuestión, no sería osado afirmar que las actas del congreso de Roma deberían considerarse como punto de partida para leer y entender el discutido libro de $H$. Küng. Es cierto que el método de trabajo es distinto. En Roma se habla con moderación, se matiza de manera científica, se precisan los conceptos con pluma analista. Pero se dicen cosas muy interesantes, principios orientadores, aunque no osan sacar las consecuencias prácticas que se derivan de ellos. Tampoco era allí necesario, dado el carácter del grupo asistente a la reunión. Merece la pena tomar en consideración algunas reflexiones claves que, de una manera o de otra, se expresaron en el Congreso de Roma.

a) El problema del lenguaje. Lo afronta $\mathrm{K}$. Rahner con el modesto título Quelques considérations sur le concept d'infaillibilité dans la théologie catholique (pp. 57-72). Los teólogos se van dando cuenta cada día más de la importancia de la analogía del lenguaje. En general, la realidad solamente puede ser expresada en términos analógicos e inadecuados; y mucho más cuando se trata de realidades conceptuales de tipo religioso. La terminología analógica está expuesta a alternativas conceptuales, no dando cabida a definiciones rigurosas de inmediata verificación empírica. Así, por ejemplo, dice el P. Rahner: "los conceptos como persona, naturaleza, pecado y caída original, eternidad, glorificación del cuerpo, infalibilidad... vienen necesariamente presentados como conceptos análogos inadecuados, de manera que una frase que les negara no sería falsa por sí misma, siempre que sea comprendida no como contradición puramente formal de la otra frase, sino como tratando de afirmar positivamente alguna cosa". Esto puede ocurrir en cualquier proposición de fe. Si digo Dios es mi Padre, puedo afirmar a continuación Dios no es mi Padre. $\mathrm{Y}$ en esta última frase tengo también razón, ya que con ese decir Dios no es mi padre estoy expresando una realidad 
humana de generación carnal por un padre humano. De ahí que ambas frases sean verdaderas, pero bajo distintos aspectos. El mismo Rahner aplica este método acerca del pecado original. Tratándose de la infalibilidad del Papa, puedo decir El Papa es infalible, pudiendo a continuación afirmar El Papa no es infalible, con tal que la segunda frase no vaya dirigida directamente contra el concepto que he querido expresar en la primera; ya que si en la segunda intento expresar el concepto de "infalible" aplicado a Dios, lógicamente este concepto es inaplicable al Papa. Se impone, pues, afirmar de nuevo el principio de Santo Tomás: Actus credentis non terminatur ad enuntiabile, sed ad rem. Exigencia necesaria de esto es que juntamente con el enunciado doctrinal haya una "reglamentación de tipo linguístico" para hecernos ver qué es lo que se intenta expresar en la formulación gnoseológica. $Y$ en este campo el teólogo deberá hacer un esfuerzo -el propiamente suyo - de ayudar a enunciar los contenidos doctrinales, emanados de la revelación, mediante expresiones más acordes a las categorías mentales de cada época y situación concreta de la historia de los hombres, destinatarios últimos del plan salvífico de Dios.

También René Marlé, en su trabajo Dogme infaillible et Herméneutique, toca la cuestión, acentuando el sentido dinámico de la fe; lo cual impone la obligación de encontrar en cada tiempo la formulación mejor para ese determinado momento histórico. Las fórmulas doctrinales, tenidas por irreformables, deben ser el punto de partida para una búsqueda crítica, búsqueda que se presenta, dentro del cuadro de la existencia humana, como indefinida (p. 309).

El problema encuentra nuevos matices en la aportación de Germano Pataro Infallibilità e Fede (pp. 313-322); ya que aún afirmando que el hablar de la Iglesia es el eco linguístico del kerigma anunciado y que la infalibilidad magisterial es el "campo" en cuyo interior se fija gnoseológicamente el dato revelado, hay que admitir que a través de los tiempos "el acento puesto sobre la infalibilidad del magisterio ha engendrado la actitud a considerar el cuerpo linguístico de la Iglesia como algo irreformable". Parece como si la exposición del Vaticano I hubiera inclinado la balanza hacia la normatividad de la palabra de la Iglesia, dejando un poco de lado la relación de la palabra de la Iglesia con la Palabra de Dios. Todo ello nos lleva a otro problema que brevemente vamos a reseñar.

b) Fe-doctrina; Fe-saivación y Vida. A través de las diversas intervenciones de la reunión de Roma se deja traslucir una lamenta- 
ción bastante común: el haber considerado, con frecuencia, la Verdad cristiana bajo un punto de vista demasiado jurídico y racionalista. René Marlé recuerda cómo ya en el s. XIX, principalmente en la escuela teológica de Tübingen, va apareciendo un movimiento tendente a corregir esta visión parcialista del contenido evangélico. La frase de Johan Adam Möhller mantiene hoy su fuerza: "El cristianismo no consiste en proposiciones, fórmulas, modos de expresión; es una vida interior, una fuerza santa; todos los conceptos y todos los dogmas no tienen otro valor más que en la medida en que ellos expresan esta realidad interior que se presupone en ellos". La relación de la formulación gnoseológica con la gran Verdad=Cristo ha encontrado en el Vaticano II una nueva actitud. El Concilio trata de orientar el pensamiento cristiano hacia una concepción interior y orgánica de las verdades de fe. Así tenemos cómo en el decreto sobre el Ecumenismo invita a reconocer, en el interior del organismo dogmático, una jerarquía, determinada por la más o menos grande proximidad de cada formulación dogmática en relación con el centro mismo del misterio: Cristo.

En nuestros días estamos ya generalmente de acuerdo en la necesidad de presentar la fe no como un cúmulo de verdades a las que se presta un asentimiento intelectual, sino más bien como una relación personal, como la aceptación de Dios que nos interpela y nos acoge. La fe implica, pues, ante todo y sobre todo una Vida, una Salvación que viene de Dios y que exige del hombre llamado una conversión, una metanoia. Es lo que Agustín de Hipona trató de hacer siempre: interiorizar totalmente el proceso personalizante de la fe, tratar de concebir ese "initium salutis" como un movimiento permanente que puntualiza e intima en cada momento la vida del creyente. De lo contrario, como afirma G. Pataro, la fe, que viene de Dios y tiene como objetivo último a Dios, pasaria a través del hombre "sin implicarle en su existencia". Lo cual contradice las enseñanzas del Maestro Jesús: convertíos y creed en el evangelio. De ahí que todo empeño por presentar la revelación en función de la salvación, haciendo ver cómo la Verdad debe ser captada como Vida y no sólo como simple ciencia o doctrina está en lo más íntimo del mensaje del Nuevo Testamento. Allá donde el "hacer no sea una hermenéutica del creer, la fe pierde su contenido y su función". No se trata de simple ortodoxia, sino de salvación y de conversión. El haber insistido casi únicamente en la importancia de las fórmulas dogmáticas ha desnivelado enormemente la balanza y ha "empobre- 
cido el problema", exponiéndolo a un extrinsicismo intelectual. Y es triste considerar cómo la historia de la Iglesia nos habla constantemente de la llamada "herejía formal" (negación de alguna verdad de fe) y se olvida con haria frecuencia de la "herejía material": Jistorsión entre lo que se dice y lo que se vive, falta de adecuación entre lo que se admite con el "intellectus" y lo que se hace con la "existencia".

Habrá, pues, que tener en cuenta dos cosas esenciales que pueden enmarcarse en un movimiento doble de significación. El primero, según G. Pataro, parte de la Palabra de Dios y alcanza la palabra del hombre, llenándola de significados que tienen sentido a partir de Dios, pero en dirección al hombre. El segundo parte de la palabra del hombre que se dispone, con toda su historicidad y según toda la gama del lenguaje humano, a expresarla. Se impone mantener la atención a las dos cosas a la vez. Si se olvida la atención a la $\mathrm{Pa}$ labra de Dios se cae en un proceso inmanentístico que reduce el hablar de Dios dentro de la area de la experiencia psicológica humana: radicalización modernista de la experiencia religiosa. $Y$ si se olvida la palabra de hombre, haciendo caso omiso del estatuto histórico del lenguaje, se exalta esa palabra y se cae en una irreformabilidad linguística que tiende a hacer prevalecer la enunciación de la verdad sobre la verdad de la enunciación. Todo ello requiere una hermenéutica del dogma como búsqueda del significado. Donde se temiese esa intervención, se sustraería el proceso dogmático a la realidad de "conversión" que le es propio, exonerándole de su relación a la Salvación (Cfr. p. 321-322).

Todo esto tiene suma importancia para la cuestión del magisterio y de la infalibilidad eclesial. Habrá que repensar y buscar el modo de expresar la relación que existe entre la infalibilidad eclesial y la historia de la salvación. El contexto ha cambiado, ya que aquí la prioridad viene concedida a la fides qua sobre la fides quae. Y por tanto, el testimonio de la fe ha de ser doble, necesariamente doble: confesión por la palabra de la Palabra que es Cristo; y confesión por la vida de la Vida que es vida en Cristo y por Cristo. De esta manera el Cristo vendrá predicado por la comunidad como Verdad expresable y como Vida "vivible". Aún más, con este panorama se ve más claro cómo la fe pertenece al entero pueblo de Dios y cómo este entero pueblo de Dios tiene una misión magisterial. El llamado "magisterio eclesiástico" asumirá una postura de servicio en cuanto certifica la fe de la comunidad, pero nunca como realidad cerrada 
y separada de la comunidad cristiana. La llamada "infalibilidac" encuentra aquí una nueva dimensión, la suya de siempre, la original: explicitación de la fides qua en la fides quae.

c) Autoridad y saber teológico. Como consecuencia de lo anteriormente expuesto surge un nuevo tema de discusión lógica: la función de la autoridad en relación a la fe o a las formulaciones de la misma. En el coloquio sobre la conferencia de $\boldsymbol{R}$. Aubert "Motivations théologiques et extra-théologiques des partisans et des adversaires de la définition dogmatique de l'infaillibilité du Pape à Vatican I (pp. 91-111) se nos presentan sugerencias dignas de consideración. Las formulaciones, aun siendo equívocas, son peligrosas. Aubert toma como ejemplo la célebre frase "ex sese non ex consensu Ecclesiae", muy apta ciertamente para echar por tierra el galicanismo y el febroniasmo, pero la historia ha comprobado cuán peligrosa y poco acertada ha sido. De hecho el Vaticano II la reinterpreta, abordando el problema bajo perspectivas nuevas. Y es que la infalibilidad lleva consigo problemas sobre el ejercicio del poder. Aubert da como seguro que Pío IX tenía un cierto sentido de la autoridad como servicio; pero estamos en "la perspectiva del despotismo ilustrado, que ha sido el sistema político del siglo XVIII en los estados italianos casi hasta el 1860 y en la Iglesia hasta más tarde todavía. Y la fórmula del despotismo ilustrado es bien elocuente: tout pour le peuple, rien par le peuple, es decir: al servicio del pueblo considerado como un niño" (p. 108). Consecuencia de esta mentalidad ha sido la elaboración de un concepto de autoridad que hoy día no nos sirve. $Y$ si esta autoridad ejerce un poder en la dirección doctrinal, entonces no hay que exirañarse si nos encontramos ante un esquema mental cerrado en el que se ha aceptado y defendido un magisterio autoritativo como realidad en sí, anterior y por encima de la comunidad, y a veces haciendo caso omiso de ella. El predominio de la Escolástica y la misma función pastoral han favorecido este proceso de identificación de la autoridad con el saber teológico (Cfr. Congar, Rev. Sc. Ph. Th. ib. p. 613). ¿Exigia esto el mundo racionalista y de anarquía intelectual en que se vivía? Lo cierto es que, principalmente a partir de Pío IX, el magisterio romano se convirtió en cuasi-monopolizador del pensamiento eclesial.

A nuestro humilde modo de entender, el problema tiene raíces más profundas. Detrás de todo este proceso está la conciencia teológica de una cuasi-identificación de la Iglesia con el Reino de Dios; 
algo así como si la Iglesia -concebida esencialmente como jerarquía durante mucho tiempo, al menos "de facto"- fuera la sociedad en que tiene vigencia eficaz y constante el Reino de lo Absoluto, de todo lo Bueno, Justo, Santo y Verdadero. Identificar Iglesia y Reino de Dios, sin más ni más, lleva congigo una autodivinización eclesial. Lo cual comporta un serio error de visión, una falta de perspec-. tiva histórica y de tensión escatológica. Así las cosas, se entiende fácilmente que el magisterio jerárquico llegara a convertirse en magis. terio eclesial; se entiende también que la autoridad jerárquica se aupara con todo el saber teológico y patrocinara aquellas escuelas ieológicas que defendian esta posición. La concepción de la Iglesia esencialmente como comunidad quedaba un tanto ahogada. Pero así es la historia, y debemos tener la suficiente humildad para reconocer cómo la Iglesia vive inmersa en el proceso de desarrollo del quehacer humano.

Con estas reflexiones, ya no nos escandalizaremos de las palabras ce G. Pataro cuando afirma: "de esta manera la infalibilidad se transforma en función institucional, de la cual solamente algunos están dotados, olvidándose de ese sensus fidelium que nos ha recordado el Vaticano II. La infalibilidad había decaído en garantía de tipo autoritativo, con todo lo que esto lleva consigo. Se ha llegado a crear, con el ejercicio de este magisterio, una situación práctica trnsformando la fe en doctrina y el Cristo en ortodoxia" (p. 322).

\section{Unfehlbar? Eine Anfrange}

Dos posturas extremas se han dejado sentir sobre este libro del profesor de Tübingen: la de aquellos agoreros de calamidades que, sin pararse a leer despacio el libro, han pronosticado la herejía del autor y la de aquellos que, también sin meditar el contenido, se han lanzado - por sistema- a una defensa a ultranza de la postura de Küng. Las aguas van volvienđo a su cauce, después de haberse gastado mucha tinta en escribir sobre el tema. Tinta que esperamos no haya sido vertida en balde, ya que toda reflexión sobre los puntos neurálgicos que toca el autor nunca será demasiada. Dos circunstancias han contribuido al éxito editorial del libro: la firma del autor y el tiempo en que aparece. La audiencia internacional de Küng no puede ponerse en duda (16.000 ejemplares en dos semanas); y las cuestiones relacionadas con la autoridad, el ministerio de Pedro, el magisterio de la Iglesia etc. son de una actualidad máxima. La bibliografía en torno al libro ha sido - y sigue siendo- de 10 más 
exuberante. Los teólogos de nombre mundial han recogico el reto de Küng y tratan de exponer su punto de vista. Se multiplican todavía hoy artículos y libros de controversia, aunque con menos apasionamiento que hace unos meses. El mismo autor ha precisado claramente su pensamiento en publicaciones ulteriores saliendo al paso de malentendidos (Cfr. Stimmen der Zeit, 186 (1970) y 187 (1971) en donde se encuentra la polémica entre el P. Rahner y Küng bajo los siguientes títulos: Kritik an Hans Küng-Zur Frage der Unfehlbarkeit theologischen Sätze; Im interesse der Sache-Antwort an $K$. Rahner.

Estas aclaraciones, así como la entrevista publicada en I C I, n. 381 ofrecen nuevas luces para enjuiciar la situación. Nuestra intención es sencilla y no pretende competir. Simplemente nos limitaremos a exponer una serie de puntos con el fin de ofrecer al lector alguna luz.

a) Finalidad de la obra. La lectura del libro -y lo hemos leído despacio- puede desilusionar a primera vista. Quien busque una tesis perfectamente elaborada con argumentación metódica $\mathrm{y}$ exhaustiva de las fuentes bíblicas, patristicas y conciliares no la enconrará. Lo que hay que preguntarse en primer lugar es si el autor pretende eso. Ciertamente que no. El autor -llevado de su amor a la Iglesia - trata de exponer una situación conflictiva actual; de ahí que el libro venga a ser como una "purga" que provoca reacción y mantiene viva la tensión de la comunidad cristiana. Por eso es de lamentar cierta critica falta de serenidad, de carácter eminentemente simplista, que ha llegado a decir de la obra de Küng que es "uno zibaldone di tutte le discipline" (Cfr. Renovatio, VI, 1971). El mismo P. Rahner, en su primer artículo de crítica severa y dura, reconoce como laudable y bueno el afán de Küng por distinguir claramente entre ley-legalismo, derecho-juridicismo, orden-inmovilismo, autoridad-autoritarismo, unidad-uniformidad... Por otra parte, el mismo autor. sale al paso de posibles acusaciones sobre su postura eclesial cuando afirma: "para esclarecer cualquier malentendido y dudas de las almas pías, el autor es y permanece siendo un teólogo católico convencido" (p. 23, edic. italiana). Habla convencido de su obligación de hacerlo, a la vez que se lamenta de "muchos teólogos que han callado, allá donde deberian haber hablado" (p. 18). Al menos hemos de aplaudir la honradez, sinceridad y postura de servicio del autor al "querer afrontar el complejo de los problemas de la autoridad magisterial eclesiástica, y en particular la cuestión especifica de 
la infalibilidad" (p. 25). Se dirige a la opinión pública para exhortar a todos a la paciencia y a la constancia en la larga marcha a través de las instituciones, ya que "nadie puede disponer del mensaje del Señor como de una propiedad exclusiva" (palabras del card. Alfrink en la clausura del concilio pastoral holandés). Existe una situación, ahí está, no tenemos más remedio que admitirla a no ser que cerremos los ojos a la evidencia. Y los teólogos no han tenido la culpa, ya que "ellos no han producido la crisis, sino que simplemente han reclamado su atención".

Con esto por delante, uno llega a comprender y a explicarse -aunque no a aplaudir- el tono ciertamente áspero, los enjuiciamientos demasiado radicales, las expresiones un tanto fuertes sobre el Papa y la Curia romana que aparecen en la "Prefazione aperta" del libro. Pero tampoco hay que sacar las cosas de juicio, ya que el autor admira la integridad del Papa, su desinterés, su vocación de servicio a la Iglesia y a la humanidad, su honestidad en obrar como obra. Lo que critica es la manera de entender y de ejercer el magisterio, apretando las filas y cerrando las ventanas abiertas en el Vaticano II.

b) Proposiciones infalibles? Hay dos cosas que el profesor Küng deja bien claras: la permanencia de la Iglesia en la verdad; y la existencia de algunos errores - de facto- en el magisterio de la Iglesia. Ambas cosas son realidades admitidas por los teólogos, historiadores, biblistas... Querer rehuir esta problemática no es honesto. Es más, se impone conciliar ambas realidades, ya que la promesa del Señor para los suyos sigue teniendo vigencia. ¿Cómo llevar a cabo esta empresa? Advirtamos el concepto bíblico de Verdad que mantiene Küng, en contraposición con el concepto intelectual que hemos estudiado en muchos manuales. La Verdad de la Iglesia es esencialmente la fidelidad a la Palabra de Dios; Palabra de Dios que debe ser "testimoniada por la Iglesia con plenitud de poder y de autoridad" Ahora bien, ¿esta Verdad de la Iglesia (que podemos llamar infalibilidad) está ligada a proposiciones infalibles? La fe, en cuanto tal, estará siempre ligada -en su expresión- a proposiciones. Es una exigencia de la misma fe, ya que la fides qua creditur comporta en seguida la fides quae creditur. Encontramos ya en el N T una serie de doxologias y de fórmulas litúrgicas que nos lo atestiguan. Con el correr del tiempo y ante enemigos de fuera, la comunidad se ve obligada a "adoptar expresiones polémicas de orden defensivo-definitorio", se ve obligada a buscar expresiones a las que el tiempo bautizó 
con el nombre de infalibles. Pero ¿la fe de la Iglesia está ligada a estas proposiciones infalibles? Küng dice que "este problema no se presentó en el Vaticano I", aunque parece que todos estaban convencidos de que la fe de la Iglesia dependiera de proposiciones propuestas como infalibles.

Se ha achacado a Küng que concibe la infalibilidad como infalibilidad de proposiciones, pudiendo así distinguir entre infalibilidad e indefectibilidad. Es verdad que, según la mejor tradición y según el mismo Vat. I, la infalibilidad es infalibilidad de juicio; juicio que necesariamente ha de tener su expresión mediante proposiciones linguísticas que nunca agotarán su contenido. De ahí que siempre esté el campo abierto a nuevas aportaciones mediante la llamada Hermenéutica conciliar. Es verdad también que las proposiciones siempre quedan encerradas en su expresión dentro del marco de lo relativo y de lo histórico, es verdad que siempre "existe una diferencia entre aquello que expreso y aquello que quiero expresar"; es verdad que "el lenguaje no es una construcción estática sino un movimiento dinámico"; es verdad que las proposiciones son "ideologizables, y con frecuencia vienen monopolizadas por una ideología determinada, por un determinado sistema, de manera que pueden llegar a expresar todo lo contrario de aquello que querían expresar en la expresión originaria". No niega Küng la necesidad de unos dogmas expresados con carácter obligatorio, lo que niega es el dogmatismo, a la vez que presenta el peligro de convertir el dogma en doctrinalismo y su obligatoriedad en juridicismo" (p. 198-199). El conferir a las expresiones de fe un carácter de instancia última comporta problemas muy serios en la historia de la Iglesia. Se afirma la permanencia de la Iglesia en la Verdad, pero es muy difícil poder afirmar la identificación del Espíritu Santo con la Iglesia jerárquica. La fe nos dice que, por encima de los pecados y de las debilidades de la Iglesia, que también es comunidad humana, está la presencia de Dios y su Palabra siempre elocuente. Esto se llama fe. $Y$ el quehacer humano es buscar, acercarse, esforzarse por ser fiel a la promesa de asistencia.

c) Infalibilidad de la Iglesia. En una Eclesiología moderna, enraizada en las fuentes bíblicas, se acentúan las categorías de 10 dinámico, de lo histórico, de lo sacramental, a la vez que se afirma la presencia del Reino de Dios, presencia que comporta la afirmación de la santidad y de la Verdad de la misma Iglesia. Por eso, Küng puede hablar de infalibilidad de la Igesia, aunque el término no le resulte grato. Efectivamente, el término infalibilidad es un tanto 
equívoco, hablando de la Iglesia, ya que encierra un contenido cuasinegativo. Habría que buscar una expresión que indicara algo más positivo. "Por eso preferimos indefectibilidad o peremnidad en la verdad. Estos conceptos de indefectibilidad o peremnidad en la verdad son conceptos más tradicionales en la Iglesia que el otro de infalibilidad" (p. 211). Y sigue afirmando: "Si la Iglesia no está en la verdad, no es Iglesia". La comunidad cristiana en cuanto sujeto eclesiológico de la fe mantiene que su fundamentación está en Dios a través de Jesús. $\mathrm{Y}$ este Jesús viene testimoniado en la Escritura $\mathrm{y}$ anunciado de nuevo en la comunidad. Y la Iglesia permanece en la verdad en cuanto se siente anclada, obediente, sujeta y esclava de ese Señor Jesucristo, Palabra del Padre.

A este respecto es interesante volver la vista atrás y repasar un poco la historia. El mismo Küng lo hace, llevado de la mano de Congar en su obra L'Eglise de Saint Augustin a l'epoque moderne (París 1970) p. 244-248, donde podemos leer cuando trata del concepto de infalibilidad en el Medievo: "La común convicción de fondo es que la Iglesia no puede equivocarse "in se" (Alberto Magno, Tomás de Aquino, Buenaventura, Decretistas). Lo que aquí se entiende es la Iglesia en su totalidad como congregatio o universitas fidelium. Esta o aquella parte de la Iglesia puede errar, también los obispos, también el Papa; pero la Iglesia permanece fiel hasta el fin. En este sentido se cita particularmente Mt. 28,20 y 16,18; Lc. 22,32; Juan 16,13. Partiendo de esta convicción de fondo a propósito de la Iglesia se forman aserciones sobre esta o aquella instancia jerárquica". Por eso Küng termina su apartado con estas palabras: "Nuestra conclusión personal es ésta: cuando respecto a la infalibilidad de los pastores y particularmente del Papa subrayamos la infalibilidad o mejor la indefectibilidad de la Iglesia y su permanecer en la Verdad, no hacemos en definitiva otra cosa que volver a una buena tradición antigua" (p. 214). Este permanecer de la Iglesia - comunidad- en la verdad es consecuencia y efecto del don de la promesa, promesa de que la Iglesia será mantenida en la verdad de Cristo. Solamente el que vive dentro de la fe puede conocer y admitir esto.

d) Magisterio directivo. La palabra "magisterio" es equívoca, ya que hay que preguntarse qué se entiende por "magisterio". Si se entiende el poder anunciar, predicar el mensaje, "entonces habrá que decir que todo cristiano debe y puede hacerlo, como consecuen- 
cia de su incorporación a la fe". Pero el término "magisterio" se ha venido usando para designar la actividad de los pastores (obisposPapa) en orden a la regulación de la verdad. Con ello se fraguó esa diferencia de la Iglesia docente-Iglesia discente. Ahora bien, dice Küng, "si por magisterio se entiende la regulación de autoridad de todas las doctrinas, por lo cual los que presiden la Iglesia sean la sola autoridad para la doctrina... entonces habría que objetar que una tal limitación, canalización y monopolización de los carismas en una hierocracia de los pastores está claramente en contradicción con el mensaje y con la Iglesia del N T"'. (p. 266-267).

No obstante, Küng es realista y ve también la necesidad de una autoridad -magisterio- directivo. Porque si dentro del mensaje del N T y dentro del Cristianismo hay alguna afirmación necesaria de fe, necesariamente también tal afirmación debe adoptar una formulación gnoseológica concreta. El problema consiste en esa "instancia" definida y concreta mediante cuya actuación se tenga la certeza de que Dios apacienta a su pueblo en la verdad. Küng no parece admitir que esa instancia (magisterio de Pastores) sea una realidad ya dada en sí y existente con anterioridad a la misma comunidad. Esa instancia - grupo directivo- es necesaria, ya que es necesaria una autoridad, como manifiesta Küng en la entrevisa de I. C. I. n. 381 . $\mathrm{Y}$ esa autoridad tiene una función para la unidad. Vendría a ser como el organismo encargado de plasmar en expresiones la fe de la comunidad. Estas mismas expresiones dogmáticas tendrian una fuerza y una obligatoriedad, aunque quedarian siempre abiertas a los nuevos cambios de los tiempos para que el lenguaje -que es dinamismo- no quede muerto. Invoca la misión de los "doctores" de tanta importancia en el N T, como los llamados a "atender a la recta interpretación del mensaje cristiano originario". Existe entre Dios y la Iglesia un lazo, una unión, pero no "un organismo jurídicamente designable, ya que afirmar una instancia última, organismo magisterial, sería identificar al Espíritu Santo con la Iglesia". El mismo Congar reconoce la necesidad de "revalorizar otros aspectos: comunidad, teólogos..." con el fin de restablecer el equilibrio. En todo este campo, el libro de Küng, termina Congar, supone un momento de crítica y de interrogación (Rev. Sc. Ph. Th. 54,1970).

e) El futuro está en marcha. Conscientemente hemos marginado el tema de la "Humanae Vitae", ya que no es más que un"caso test" para plantear el problema de la autoridad y del magisterio eclesiástico". No es que Küng dramatice, como ha escrito Charpe en 
ICI, n. 381, la situación en torno a este espinoso problema de la regulación de los nacimientos. Sobradamente conoce el profesor de Tübingen que la encíclica de Pablo VI no es un acto del magisterio extraordinario y que, por tanto, no tiene "en sí" el carácter de infalible. Pero tampoco podemos olvidar que, siguiendo una teología extremista de manual, tal doctrina, en cuanto mantenida por tres $\mathrm{Pa}$ pas y por el conjunto del episcopado, ha llegado a aparecer -de facto- como cuasi-infalible. Sea lo que fuere del problema, se trata de un punto de reflexión que ofrece al autor una coyuntura estupenda para plantear, "con un radicalismo que raya en la simplificación y con un coraje que confina con la intrepidez", la tesis de la verdad en la Iglesia. Las jerarquías de Roma han tomado la cuestión en serio y está en marcha un estudio conjunto de la situación. ¡Con cuanto afán desearíamos todos un diálogo abierto, sereno, cristiano en torno a estos temas! Y el futuro está ahí, ya que no se trata de buscar víctimas expiatorias, sino de afrontar el futuro de la comunidad cristiana. Una vez más se nos exige una confianza plena en la asistencia del Espíritu. Y una vez más se nos intima a trabajar, a luchar, a buscar. Lo divino y lo humano se entremezclan en esta Iglesia "acontecimiento e institución". Lo importante es dejar a Dios su parte, a la vez que se reconoce la tarea y el quehacer del hombre. A pesar de todo, me permito opinar que debemos estar agradecidos al autor del libro. Le hubiera sido mucho más fácil y cómodo callarse, como él mismo ha manifestado. Pero ha optado por lo difícil, por el riesgo, por el interrogante. Ahora nos toca a todos -en comunidad de amor y de servicio- ofrecer una respuesta. Esta misma idea insinúan los textos de Agustín que Küng pone al principio y al final de su trabajo.

Alfonso GarRIDO

Valladolid, julio 1971 